\title{
A Review of Nutrients to Extend Healthspan and Avoid Cancer by Reducing the Amount of Protein Misfolding, Free Radicals, and Calcification
}

\author{
Alfred Ordman \\ Beloit College, Beloit, WI, USA \\ Email: ordman@beloit.edu
}

How to cite this paper: Ordman, A. (2020) A Review of Nutrients to Extend Healthspan and Avoid Cancer by Reducing the Amount of Protein Misfolding, Free Radicals, and Calcification. Journal of Cancer Therapy, 11, 497-506.

https://doi.org/10.4236/jct.2020.118043

Received: June 1, 2020

Accepted: August 22, 2020

Published: August 25, 2020

Copyright $\odot 2020$ by author(s) and Scientific Research Publishing Inc. This work is licensed under the Creative Commons Attribution International License (CC BY 4.0).

http://creativecommons.org/licenses/by/4.0/

\begin{abstract}
Two major causes of human aging include protein misfolding and free radicals. Protein misfolding occurs when proteins which are synthesized by cells do not have the proper amino acid sequence or do not achieve the correct three-dimensional configuration to function properly. Peer-reviewed scientific literature explains how these processes contribute to many age-associated diseases. A few examples include cancer, heart disease, dementias including Parkinson's and Alzheimer's diseases, and arthritis. This article reviews how protein misfolding can be slowed and even reversed by appropriate nutrition, potentially slowing and reversing these diseases. One cause of misfolding is mRNA translation occurring too rapidly for proper chaperone binding or protein folding. A second cause is deficiency of amino acids so improper tRNA binding occurs. A third cause is free radicals. They cause mutations promoting misfolding and cancer, and oxidize lipoproteins causing plaque in circulation promoting heart disease and stroke. Nutrients with proven actions will contribute to longer healthspans for our aging population. Healthspan is the number of healthy years before chronic or terminal diseases substantially impair the quality of life. This can be done especially by slowing and reversing these three causes of PM. Niacin, quercetin, EGCG, alpha-lipoic acid, $\mathrm{N}$-acetyl-carnitine, tyrosine and cysteine address protein misfolding. Vitamin $\mathrm{C}$ and glutathione trap free radicals. Vitamin $\mathrm{K}$ amplifies free radical cancer killing by vitamin $\mathrm{C}$ and activates decalcification enzymes which remove calcium deposits in the circulatory system and strengthen bones. Apigenin activates the pathway of caloric restriction and induces cancer cell apoptosis. This article provides citations and explanations of the progress showing new
\end{abstract}


ways to maintain health as we age. For convenience and cost savings, many of these ingredients can be consumed in supplement form, taken twice a day to maintain water-soluble nutrient levels.

\section{Keywords}

Protein Misfolding, Healthspan, Cancer, Alzheimer's, Arthritis, Decalcification, Apigenin

\section{Introduction}

The pandemic of aging is causing tremendous suffering and expense that can be relieved by greater education about the benefits of proper nutrients to prevent or delay the onset of cancer, heart disease, dementias, and other age-associated diseases. Until recently, the Mayo Clinic website maintained that vitamin C had no effect on cancer. On June 11, 2019 the American Association of Retired People magazine had an article stating that brain supplements do not work. Most medical schools provide only a day of education about the effect of nutrition on health.

But a major cause of age-associated diseases (AADs) is a recently discovered metabolic process called protein misfolding (PM) [1] [2]. The basic concept of PM is that as we age, our bodies synthesize proteins too rapidly. Because of insufficient time to find the proper amino acids during translation or enough time during synthesis for them to fold into the proper shape to function correctly, our cells make dysfunctional proteins. When we are young, these are degraded by proteasomes [3]. But as we age, they accumulate more quickly, clump together, and form globs too large for proteasomes to degrade.

PM contributes to AADs, including cancer, Alzheimer's, Parkinson's, strokes, and dementia. Misfolded proteins cause pathogenic aggregation, causing cancer [4], even harming tumor suppressor p53 [5]. PM is a precursor to Alzheimer's and can be detected at least 14 years prior to symptoms [6]. This leads to mitochondria unable to produce energy, senescent cells that persist and produce harmful signals, and plaque consisting of dysfunctional proteins. In peer-reviewed scientific publications specified below, nutrients are reported to reduce PM and other age-related declines and diseases. So supplementation with these nutrients now can be effective to reduce cancer, dementias, heart disease, and other AADs.

In the general circulatory system, plaque consisting of macrophages bloated from consuming oxidized low-density lipoproteins (ox-LDL) contributes to heart disease. In the brain, both forms of plaque contribute to memory loss, Alzheimer's, Parkinson's, and other dementias [7]. So reducing both forms of plaque, from PM and ox-LDL, is likely to significantly increase healthspan of the body and brain.

Research has shown that caloric restriction (CR) substantially lengthens the lives of animals, and reduces the rate of AADs, extending life $600 \%$ in C. elegans. 
$\mathrm{CR}$ involves maintaining all essential nutrients in the diet, while reducing caloric intake substantially. Even 12 hours of fasting on a regular basis have been shown to improve the health of humans. Recently a biochemical mechanism for this has been identified [8]. It involves inhibition of translation, slowing protein synthesis so errors in amino acids and protein folding are lessened. This indicates that a process which can reduce PM will slow declines from aging.

\section{Methods}

As a professor at Beloit College, I have published research on antioxidants [9] [10] while distributing a newsletter [11] summarizing new scientifically-based nutrition results that may contribute to healthspan. Upon retiring after 38 years, I was invited to develop nutritional supplements likely to reduce age-related decline. Aware of the vast quantity of deceptive and hazardous supplements, I reviewed the commercial products and scientific literature to determine what uncommon but safe nutrients with proven mechanisms to extend healthspan would be useful in a supplement (Table 1). The scientific basis of the ingredients in Triumph that reduce the risk for cancer and heart disease was described previously in J Cancer Therapy [12]. Here I describe additional nutrients recently shown to reduce the risk for those and other AADs.

Table 1. Justification of nutrients.

\begin{tabular}{|c|c|c|}
\hline Nutrient & Benefit & References \\
\hline Vitamin C $250 \mathrm{mg}$ & $\begin{array}{l}\text { Antioxidant, reduces risk of stroke damage, } \\
\text { amplified may kill cancer cells, reduces } \\
\text { formation of plaque in arteries and brain }\end{array}$ & {$[7][9][10][12]$} \\
\hline Vitamin K 75 mcg & $\begin{array}{l}\text { Activates decalcification enzymes, } \\
\text { amplifies vitamin C ability to kill cancer cells }\end{array}$ & {$[12][13][14]$} \\
\hline Niacinamide $5 \mathrm{mg}$ & $\begin{array}{l}\text { Diminishes with age, required to } \\
\text { maintain NAD for energy production }\end{array}$ & {$[15][16]$} \\
\hline Quercetin $25 \mathrm{mg}$ & $\begin{array}{l}\text { Antioxidant which prevents degradation } \\
\text { of EGCG }\end{array}$ & {$[17][18]$} \\
\hline EGCG $40 \mathrm{mg}$ & $\begin{array}{l}\text { With quercetin, slows translation, } \\
\text { is antibiotic, and improves health }\end{array}$ & {$[17][18][19]$} \\
\hline $\begin{array}{l}\text { Alpha Lipoic Acid } 25 \mathrm{mg} \\
\text { (ALA) }\end{array}$ & $\begin{array}{l}\text { Decreases with age, required } \\
\text { for Citric acid cycle for energy }\end{array}$ & [20] \\
\hline $\begin{array}{l}\text { N-Acetyl-L-Carnitine } \\
\text { HCl } 25 \text { mg (NAC) }\end{array}$ & $\begin{array}{l}\text { Decreases with age, required to } \\
\text { transport fatty acids into the mitochondria }\end{array}$ & {$[20]$} \\
\hline L-Tyrosine $25 \mathrm{mg}$ & Amino acid deficient in most diets & {$[21]$} \\
\hline $\begin{array}{c}\text { Setria } \\
\text { (L-Glutathione Reduced) } 25 \mathrm{mg}\end{array}$ & $\begin{array}{l}\text { Antioxidant that contains cysteine, } \\
\text { an amino acid deficient in most diets }\end{array}$ & {$[21]$} \\
\hline Citrus Bioflavonoids $25 \mathrm{mg}$ & Antioxidants also including apigenin & $\begin{array}{c}{[8][22]} \\
{[23][24][25]}\end{array}$ \\
\hline $\begin{array}{c}\text { Parsley Leaf } \\
15 \mathrm{mg}=2.1 \mathrm{mg} \text { apigenin }\end{array}$ & $\begin{array}{l}\text { Mimics caloric restriction, restores NAD } \\
\text { levels, causes apoptosis of cancer cells }\end{array}$ & $\begin{array}{l}{[8][22]} \\
{[23][24][25]}\end{array}$ \\
\hline
\end{tabular}




\section{Results}

Three mechanisms of aging have been hypothesized for many years: free radicals [26], inflammation [27], and telomeres [28]. Causes and strategies to reduce these processes have been proposed [29] (Table 2). More recently, protein misfolding (PM), has been identified as a major cause of decline as we age [30]. PM contributes to cancer, Alzheimer's, Parkinson's, and other age-associated diseases such as arthritis [15]. To reduce the amount of PM, specific nutrients have been identified with proven mechanisms of action.

I cite below specific nutrients that are likely to slow the rate of PM (Table 3). These nutrients are Generally Recognized As Safe (GRAS) by the Food and Drug Administration, and can be incorporated into supplements which may slow the epidemic of Alzheimer's and other age-related diseases that are related to PM.

EGCG (Epigallocatechin gallate) slows the transcription process so proteins can fold properly. Quercetin inhibits the enzyme which degrades EGCG. Thus, consuming the amount of quercetin in one serving of blueberries along with the

Table 2. Mechanisms of human aging.

\begin{tabular}{ccc} 
Cause 1 & $\begin{array}{c}\text { Free radical } \\
\text { theory of aging }\end{array}$ & $\begin{array}{l}\text { A primary risk reduced by Mito-C. Radicals contain unpaired } \\
\text { electrons which cause a variety of damage, especially plaque } \\
\text { in arteries and DNA mutations. }\end{array}$ \\
Cause 2 & Inflammation & $\begin{array}{l}\text { Especially low level chronic inflammation caused by stress, } \\
\text { trans fats and omega-6 fatty acids, this degrades the immune } \\
\text { system and promotes obesity, diabetes, and cancer. }\end{array}$ \\
Cause 3 & $\begin{array}{c}\text { Telomere } \\
\text { shortening }\end{array}$ & $\begin{array}{l}\text { This causes cellular senescence. Major causes are diet and stress. } \\
\text { Polyphenols in Mito-C preserve telomeres. }\end{array}$ \\
Cause 4 & $\begin{array}{c}\text { Protein } \\
\text { misfolding }\end{array}$ & $\begin{array}{l}\text { A primary risk reduced by Mito-C. PM causes deficiencies in } \\
\text { effective metabolism, cellular senescence, and protein } \\
\text { aggregation as found in Alzheimer plaque. }\end{array}$ \\
Cause 5 & $\begin{array}{c}\text { Microbiome } \\
\text { destruction }\end{array}$ & $\begin{array}{l}\text { Loss of healthy microbes in the intestines is especially caused } \\
\text { by antibiotics, deficient fiber in the diet. }\end{array}$ \\
Cause 6 & $\begin{array}{l}\text { Cellular } \\
\text { senescence }\end{array}$ & $\begin{array}{l}\text { Caused by causes } 1 \text { - 4, loss of stem cells particularly can have } \\
\text { cascading effects on other metabolic systems. }\end{array}$ \\
\hline
\end{tabular}

See https://www.nutritionconsensus.org/whyweage for citations and details.

Table 3. How literature was evaluated.

\begin{tabular}{|c|c|}
\hline Step 1 & $\begin{array}{l}\text { Peer-reviewed distinguished scientific literature Science, Nature, } \\
\text { J. Cancer Therapy, Am Soc Nutrition Journals } \\
\text { Select nutrients that are described as reducing age-associated diseases }\end{array}$ \\
\hline Step 2 & $\begin{array}{l}\text { Review secondary sources in peer-reviewed journals } \\
\text { Look for evidence in vitro and in vivo studies demonstrating effectiveness }\end{array}$ \\
\hline Step 3 & Review ingredients to ensure safety and that synergistic effects are beneficial \\
\hline Step 4 & $\begin{array}{l}\text { Determine whether combined ingredients are already available in common } \\
\text { supplements like AREDs }\end{array}$ \\
\hline Step 5 & Determine useful human dosage and frequency based on capsule size \\
\hline
\end{tabular}


EGCG content of a serving of green tea can provide an EGCG timespan in the body equivalent to the benefit of 6 cups of green tea. Quercetin blocks the action of the enzyme responsible for degrading EGCG, which is the active ingredient in green tea [17]. Servings of green tea consumed daily have been shown to be correlated with health. The health benefit has been shown to increase linearly from zero to 4 cups of green tea daily [18]. This reduces protein misfolding and activates the beneficial processes similar to those of dietary restriction.

In addition, EGCG has antibiotic (Ab) effects, particularly enhancing Ab effectiveness against Ab-resistant bacteria. Researchers at the University of Surrey combined EGCG with many types of antibiotics, finding the combination was up to $31 \%$ more effective at killing off harmful bacteria compared to the drug antibiotic alone [19].

Deficiency of the amino acids tyrosine and cysteine contributes to protein misfolding during transcription. Many diets are deficient in these 2 amino acids, and people in regions of the world where people live longest have higher levels of these 2 amino acids in their diets. These findings are based on work with Rolf Martin [21]. When the diet is deficient in these, phenylalanine and alanine are likely to be substituted in tRNAs, so when the protein is synthesized, it misfolds because the wrong side chains are present.

Bioflavonoids in addition to quercetin have numerous health benefits. It was recently discovered that one bioflavonoid, apigenin [22], mimics the metabolic pathway effect of caloric restriction. It inhibits CD 38, also known as cyclic ADP ribose hydrolase, a glycoprotein found on the surface of many immune cells. Apigenin restores NAD+ toward more youthful levels. It also induces cancer cell apoptosis or autophagy and attenuates cancer cell proliferation or metastasis [25]. Parsley is a rich source of apigenin, but also has been praised as a dietary source of many other benefits. "[A] wide range of pharmacological activity including antioxidant, hepatoprotective, brain protective, anti-diabetic, analgesic, spasmolytic, immunosuppressant, anti-platelet, gastroprotective, cytoprotective, laxative, estrogenic, diuretic, hypotensive, antibacterial and antifungal activities have been exhibited for this plant in modern medicine" [23] [24]. Based on the work of Ordman [10], $500 \mathrm{mg}$ of vitamin C twice a day will maintain near its highest concentration in people's blood. There are numerous likely benefits. A major cause of plaque in the arteries and the brain is oxidized low-density lipoprotein (ox-LDL). When free radicals are generated in the blood, if there is inadequate vitamin $\mathrm{C}$ to maintain the reduction of LDL, ox-LDL is formed. Macrophages recognize this as a foreign molecule, consume it, and turn into foam cells. It is these cells that are sticky, attach to the circulatory system, for instance in small capillaries in the brain, and produce plaque [7]. Besides heart disease, this plaque can contribute both to major and mini-strokes, harming brain function. Another molecule that traps free radicals is glutathione, often called the body's master antioxidant. It also provides cysteine to help prevent protein misfolding, as described above. 
Alpha-lipoic acid (ALA), N-acetyl-carnitine (NAC) and niacinamide are nutrients known to diminish with age [20]. All three are vital to brain function and energy. NAC transports fatty acids into the mitochondrion, and ALA aids their degradation to generate energy. NAD+ levels diminish with age [15] and are replenished by supplemental niacinamide [16].

Vitamin $\mathrm{K}$ is another nutrient recently discovered to have great benefit when consumed at levels far above the Daily Value. Calcification of the heart, arteries, and other organs is a major contributor to AADs. Excess calcium causes deposits in the heart and arteries, making both less flexible and effective. Nearly everyone in the US gets adequate calcium in the diet, and supplemental calcium is hazardous, so older Americans benefit from decalcification (DC). DC is a process by which excessive calcium deposits that form in the heart and circulatory system are removed [13]. The higher level of vitamin $\mathrm{K}$ has been shown by metabolomic analysis to activate a variety of decalcifying enzymes. These Vitamin K-induced enzymes decalcify soft tissues where excess calcium causes harm [14]. You may maintain a healthier blood pressure and have a better cardiac rhythm. This may have numerous other health benefits. You are less likely to break a hip. You are more likely to maintain a stronger bone mass. And it will benefit your brain by reducing your risk for Alzheimer's and Parkinson's diseases.

\section{Discussion}

The number of scientists alive today is greater than all who have lived previously. The level of medical knowledge is projected to double every 7 months by 2020. Because of an abundance of deceptive products and claims, we are not effectively informed of the great increase in knowledge of the benefits of proper nutrition.

As examples, in 2019 the pathway by which dietary restriction [DR] slows the aging process was discovered [8]. DR slows the process by altering a signal so that proteins are synthesized more slowly, reducing the rate of PM. Apigenin affects the pathway just as DR does [22]. Also, consuming quercetin and EGCG has an effect similar to DR, without the need to fast for $12 \mathrm{hr}$ or longer.

To reinforce how these nutrients particularly reduce PM, here is a summary (Table 4). Vitamin C reduces free radicals, which damage DNA, so improper amino acid sequences may result. It also oxidizes cysteine, which can prevent crosslinks that maintain protein conformation. EGCG and quercetin slow the process of translation, so that the proper tRNAs can bind as the protein is synthesized, and so the nascent protein has time to recruit the correct chaperones and assume the specific $3 \mathrm{~d}$ conformation. Tyrosine and cysteine in Glutathione are 2 amino acids deficient in most diets. When deficient, mRNA will recruit mismatched tRNAs that insert incorrect amino acids. ALA, NAC, and niacinamide are nutrients that diminish with age, and are essential for energy metabolism, producing the NADH and ATP required for the proper completion of all of the steps of protein synthesis. As many of these ingredients are water-soluble 
Table 4. Examples of impact of nutrients on disease.

\begin{tabular}{|c|c|}
\hline Nutrients & Scientific Evidence for Health Impact \\
\hline Vitamin C & $\begin{array}{l}\text { Recently many studies have indicated the benefit of high levels of AA to } \\
\text { maintain the brain, bones, and heart, reduce damage from stroke, brain } \\
\text { trauma, and cataracts, and lower the risk of cancer metastasis and colds [31]. }\end{array}$ \\
\hline Vitamin $\mathrm{K}$ & $\begin{array}{l}\text { Aortic stenosis is a common but fatal disease when it becomes } \\
\text { symptomatic, specially if not treated... The investigators hypothesize that } \\
\text { MK-7 supplementation may slow or even reverse the progression } \\
\text { of the disease process [32]. }\end{array}$ \\
\hline ALA and NAC & $\begin{array}{l}\text { Thus, acetyl carnitine/alpha-lipoic acid dietary supplements have a } \\
\text { potential market of tens of millions of middle-aged and elderly } \\
\text { Americans who desire to improve their general health [33]. }\end{array}$ \\
\hline $\begin{array}{l}\text { Quercetin } \\
\text { and } \\
\text { EGCG }\end{array}$ & $\begin{array}{l}\text { Benefits of consumption of these nutrients include anti-inflammatory, } \\
\text { antipathogenic and antioxidant activities; immunoregulatory influences; } \\
\text { and central nervous system and muscle mitochondrial biogenesis } \\
\text { stimulatory effects [34]. }\end{array}$ \\
\hline $\begin{array}{l}\text { Apigenin and } \\
\text { Caloric } \\
\text { Restriction }\end{array}$ & $\begin{array}{l}\text { Benefits possibly involve significant alterations in energy metabolism, } \\
\text { oxidative damage, insulin sensitivity, inflammation, and functional } \\
\text { changes in both the neuroendocrine and sympathetic nervous systems [35]. }\end{array}$ \\
\hline
\end{tabular}

nutrients, they must be consumed twice a day to prevent inadequate availability, which is a problem with most nutritional supplements.

\section{Conclusion}

Protein misfolding is a cause of age-related decline in health. Based on the above findings, it is appropriate to combine protective ingredients into a daily supplement which has been done by MDR in their Mito-C Formula for a healthy mind and body. One can obtain these various nutrients separately, but the importance is to increase their intake above what is typically derived in the American diet. By doing so it will help contribute to public health and longevity and may reduce the risk of some diseases associated with aging.

\section{Disclosure}

I was hired as a consultant by Medical Doctors Research (MDR) to develop a supplement to support longevity. I investigated what nutrients would extend healthspan that is not present in most supplements. Based on the above information, MDR has manufactured a supplement, Mito-C, with safe and inexpensive nutrients to maintain the health of our brains and reduce the risk of diseases, especially cancer, associated with aging.

\section{Acknowledgements}

MDR sponsored this publication and markets the Mito-C supplement on MDR.com based on my research and formulation guidelines.

\section{Conflicts of Interest}

The author declares no conflicts of interest regarding the publication of this paper. 


\section{References}

[1] Kikis, E.A., Gidalevitz, T. and Morimoto, R.I. (2010) Protein Homeostasis in Models of Aging and Age-Related Conformational Disease. Advances in Experimental Medicine and Biology, 694, 138-159. https://doi.org/10.1007/978-1-4419-7002-2_11

[2] SENS Research Foundation (2019) The Root Causes of Aging. https://www.fightaging.org/archives/2019/06/exosomes-in-harmful-senescent-cell-s ignaling

[3] Tanaka, K. (2009) The Proteasome: Overview of Structure and Functions. Proceedings of the Japan Academy Series B: Physical and Biological Sciences, 85, 12-36. https://doi.org/10.2183/pjab.85.12

[4] Nagaraj, N.S., Singh, O.V. and Merchant, N.B. (2010) Proteomics: A Strategy to Understand the Novel Targets in Protein Misfolding and Cancer Therapy. Expert Review of Proteomics, 7, 613-623. https://doi.org/10.1586/epr.10.70

[5] Gong, H., Yang, X., Zhao, Y.B., Petersen, R., Liu, X., Liu, Y. and Huang, K. (2015) Amyloidogenicity of p53: A Hidden Link between Protein Misfolding and Cancer. Current Protein and Peptide Science, 16, 135-146. https://doi.org/10.2174/1389203715666141128115649

[6] Stocker, H., et al. (2019) Prediction of Alzheimer's Disease Diagnosis within 14 Years through a $\beta$ Misfolding in Blood Plasma Compared to APOE4 Status, and Other Risk Factors. Alzheimer's \& Dementia, 20, 283-291. https://doi.org/10.1016/j.jalz.2019.08.189

[7] NIH (2019) Causes of Alzheimer's Disease: What Happens to the Brain in Alzheimer's Disease? https://www.nia.nih.gov/health/what-happens-brain-alzheimers-disease

[8] Hahm, J., Jeong, C. and Nam, H. (2019) Diet Restriction-Induced Healthy Aging Is Mediated through the Immune Signaling Component ZIP-2 in Caenorhabditis elegans. Aging Cell, 18, e12982. https://doi.org/10.1111/acel.12982

[9] Folk, E., Downs, T. and Ordman, A.B. (2015) Two Grams BID Is an Oral Dosage of Vitamin C to Reduce the Risk of Recurrence of Superficial Bladder Carcinoma. Journal of Cancer Therapy, 6, 169-176. https://doi.org/10.4236/jct.2015.62019

[10] King, G., Ordman, A.B., et al. (1994) Rate of Excretion of Vitamin C in Human Urine. Age, 17, 87-92. https://doi.org/10.1007/BF02435011

[11] Ordman, A.B. (2020) Nutrition Research Article Summaries and Links. Pre-2004 to Present. http://www.nutritioninvestigator.org/Nutrition/indices/isub.htm

[12] Ordman, A. (2010) Vitamin C Twice a Day Enhances Health. Health, 2, 819-823. https://doi.org/10.4236/health.2010.28123

[13] Miedema, M.D., Blaha, M.J., et al. (2019) Association of Coronary Artery Calcium with Long-Term, Cause-Specific Mortality among Young Adults. JAMA Network Open, 2, e197440. https://doi.org/10.1001/jamanetworkopen.2019.7440

[14] Maresz, K. (2015) Proper Calcium Use: Vitamin $\mathrm{K}_{2}$ as a Promoter of Bone and Cardiovascular Health. Integrated Medicine (Encinitas), 14, 34-39.

[15] Darnell, J.C. (2014) Ribosome Rescue and Neurodegeneration. Science, 345, 378-379. https://doi.org/10.1126/science.1257193

[16] Johnson, S. and Imai, S. (2018) NAD + Biosynthesis, Aging, and Disease. F1000Research, 7, 132. https://doi.org/10.12688/f1000research.12120.1

[17] Wang, P., Heber, D. and Henning, S.M. (2012) Quercetin Increased the Antiproliferative Activity of Green Tea Polyphenol (-)-Epigallocatechin Gallate in Prostate 
Cancer Cells. Nutrition and Cancer, 64, 580-587. https://doi.org/10.1080/01635581.2012.661514

[18] Blumberg, J. (2012) Proceedings of the Fifth International Scientific Symposium on Tea and Human Health. USDA.

[19] Lee, S., Razqan, G.S. and Kwon, D.H. (2017) Antibacterial Activity of Epigallocatechin-3-Gallate (EGCG) and Its Synergism with $\beta$-Lactam Antibiotics Sensitizing Carbapenem-Associated Multidrug Resistant Clinical Isolates of Acinetobacter baumannii. Phytomedicine, 15, 49-55. https://doi.org/10.1016/j.phymed.2016.11.007

[20] Ames, B.N. (2009) Mitochondrial Decay in the Brains of Old Rats: Ameliorating Effect of Alpha-Lipoic Acid and Acetyl-L-Carnitine. Neurochemical Research, 34, 755-763. https://doi.org/10.1007/s11064-008-9850-2

[21] Chaudhuri, T.K. and Paul, S. (2009) Protein-Misfolding Diseases and Chaperone-Based Therapeutic Approaches. Neurochemical Research, 34, 755-763.

[22] Escande, C., Chini, E.N., et al. (2013) Flavonoid Apigenin Is an Inhibitor of the $\mathrm{NAD}+$ ase CD38: Implications for Cellular NAD+ Metabolism. Diabetes, 62, 1084-1093. https://doi.org/10.2337/db12-1139

[23] Allam, A.A., Ajarem, J., et al. (2016) Protective Effect of Parsley Juice (Petroselinum crispum, Apiaceae) against Cadmium Deleterious Changes in the Developed Albino Mice Newborns (Mus musculus) Brain. Oxidative Medicine and Cellular Longevity, 2016, Article ID: 2646840. https://doi.org/10.1155/2016/2646840

[24] Farzaei, M.H. and Farzaei, F. (2013) Parsley: A Review of Ethnopharmacology, Phytochemistry and Biological Activities. Journal of Traditional Chinese Medicine, 33, 815-826. https://doi.org/10.1016/S0254-6272(14)60018-2

[25] Yan, X., Shao, H., et al. (2017) Apigenin in Cancer Therapy: Anti-Cancer Effects and Mechanisms of Action. Cell \& Bioscience, 7, 50.

https://doi.org/10.1186/s13578-017-0179-x

[26] Harman, D. (1988) Free Radical Theory of Aging: Current Status. In: Zs.-Nagy, I., Ed., Lipofuscin-1987: State of the Art, Elsevier, New York, 3-21.

[27] Chung, H.Y., et al. (2019) Redefining Chronic Inflammation in Aging and Age-Related Diseases: Proposal of the Senoinflammation Concept. Aging and Disease, 10, 367-382. https://doi.org/10.14336/AD.2018.0324

[28] Shamas, M.A. (2011) Telomeres, Lifestyle, Cancer, and Aging. Current Opinion in Clinical Nutrition \& Metabolic Care, 14, 28-34. https://doi.org/10.1097/MCO.0b013e32834121b1

[29] Ordman, A.B. (2014) The Translational Error Theory of Human Aging. http://www.nutritioninvestigator.org/Nutrition/translation.htm

[30] Marinko, J.T., Sanders, C.R., et al. (2019) Folding and Misfolding of Human Membrane Proteins in Health and Disease: From Single Molecules to Cellular Proteostasis. Chemical Reviews, 119, 5537-5606. https://doi.org/10.1021/acs.chemrev.8b00532

[31] Ordman, A. (2019) Nutritional Steps to Maintain Health and Reduce Cancer Risk. Journal of Cancer Therapy, 10, 829-834. https://doi.org/10.4236/jct.2019.1010070

[32] Peeters, F., et al. (2018) Bicuspid Aortic Valve Stenosis and the Effect of Vitamin K2 on Calcification Using 18F-Sodium Fluoride Positron Emission Tomography/Magnetic Resonance: The BASIK2 Rationale and Trial Design. Nutrients, 10, 386. https://doi.org/10.3390/nu10040386

[33] Document Prepared for the National Cancer Institute, Acetyl-L-Carnitine/-Lipoic 
Acid 5080-50-2/62-46-4.

https://ntp.niehs.nih.gov/ntp/htdocs/chem_background/exsumpdf/carnliposupp_50 8.pdf

[34] Nieman, D.C., et al. (2009) Effects of Quercetin and EGCG on Mitochondrial Biogenesis and Immunity. Medicine \& Science in Sports \& Exercise, 41, 1467-1475. https://doi.org/10.1249/MSS.0b013e318199491f

[35] Redman, L.M. and Ravussin, E. (2011) Caloric Restriction in Humans: Impact on Physiological, Psychological, and Behavioral Outcomes. Antioxidants \& Redox Signaling, 14, 275-287. https://doi.org/10.1089/ars.2010.3253 